\title{
A Critical Analysis of Some of the Arguments fOr the IllegitimaCy OF RATIONAL INVESTIGATION IN RELIGION
}

\author{
Shiraz Husain Agha \\ Faculty of Philosophy, Al-Mustafa International University, \\ Qom, I. R. Iran
}

The permissibility of rational investigation into matters of religion is a topic that has always been a subject of debate among Muslim scholars. It is even possible to categorize the various sects within the Islamic world based upon their view regarding this subject. Some Muslim scholars went to extremes in their rational investigations, to the extent that they attempted to prove any and every religious verity by means of logic and reason. Others were at the opposite end of the spectrum in that they rejected all forms of rational discourse and said that the sole way to attain the truth is by means of a blind imitation of religion. Of course, there were many groups between the two. This paper seeks to critically analyze some of the arguments of the group of scholars who say that it is absolutely impermissible to use reason to understand religion. These arguments revolve around the comprehensiveness of the Qur'an, the idea that useful knowledge only belongs to the pious, the fact that rational investigation leads to the rejection of the apparent meanings of the religious texts, that rational investigation was introduced in the Islamic world with evil motives, that it sometimes leads to incorrect conclusions, that it leads to a vicious circle of argumentation, the idea that people often arrive at correct conclusions without the need for logic, that reality does not observe the formal laws of logic, etc. There are some objections that are common to all of these arguments and there are some that are specific to each one of them. In brief, none of these arguments are sound.

Keywords: reason, logic, religion, legitimacy, Qur'an, Sunnah 


\section{Introduction}

The relation between reason and religion is a topic that has intrigued thinkers from time immemorial. This subject can be approached from many different angles. Nevertheless, the most important question of them all is whether reason has the ability to comprehend religious truths without the help of religion. People have presented different answers to this question. In fact, it is even possible to divide the various intellectual trends within Islam based upon their approach to this question. On the one hand, there are some, such as the Ash'arites, the Ahl al-Hadith, the Akhbaris, the Tafkikis, and the mystics, who have diminished the role of reason. On the other hand, there are groups such as the Mu'tazilites, the Usulis, and the philosophers who have stressed this role. Each group has its own arguments and premises. In this paper we will analyze some of the evidence for the illegitimacy of the use of rational investigation of religious truths. Most of these truths are analytical in nature and, as we will see, this is a problem that is common to all of them. Some of them rely on some verses of the Qur'an and the traditions of the Infallibles. However, as we shall see, these religious texts have nothing to do with the subject at hand. Many of these proofs do not have the ability to prove the absolute illegitimacy of rational investigation that these people are attempting to establish. Thus, these pieces of evidence are not harmonious with the claim they are attempting to prove. Also, if some of these pieces of evidence were valid, they would lead to the illegitimacy of many other non-rational sciences, which is something that their proponents do not agree with. There are also problems that are specific to each argument. All in all, none of these pieces of evidence has the ability to prove the illegitimacy of rational investigation of religious truths. It should not be left unsaid that the opponents of rational investigation also have answers to the arguments of the proponents of rational investigation. However, this is a topic that demands an independent investigation.

\section{$1^{\text {st }}$ Objection: The Comprehensiveness of the Qur'an and the Sunnah}

\section{Objection:}

If everything that man needs is contained in the Quran and the Sunnah, then there is no need to seek knowledge from any source other than the two. However, everything that man needs is contained in the Qur'an and the Sunnah. Therefore, there is no need for anyone to seek knowledge from any source other than the Qur'an and the Sunnah. Being a useless endeavor, seeking knowledge from any source other than the Qur'an and the Sunnah 
would have to be illegitimate. Since rational investigation is a source other than the Qur'an and the Sunnah, it would therefore be illegitimate to refer to it (Jawadi Amuli 1985: 88).

\section{Critique:}

First of all, this argument is a composite syllogism, the first two parts of which is an exceptive syllogism and the third part of which is a categorical syllogism. Thus, the conclusion of this argument contradicts it. Therefore, it must be rejected.

Secondly, we do not accept the minor premise of the categorical syllogism in this argument, i.e. the idea that "rational investigation is a source other than the Qur'an and the Sunnah". Rational investigation is not parallel to the Qur'an and the Sunnah; rather, it is one of the essential parts of these two entities. This is because in many instances rational investigation can be found in these two sources of wisdom. A prime example of this are the rational arguments that the Infallible Imams had with the adherents of other faiths. One has only to look at the debates that Imam Ridha conducted in the courtyard of Ma'mun to verify this fact (Jawadi Amuli 2001: 26-29).

Thirdly, if this argument were valid, it would lead to the impermissibility of many other sciences such as Arabic grammar, etc. This is because if rational investigation is parallel to the Quran and the Sunnah, then there is no reason not to state the same thing for these sciences as well. However, this is not something that the person presenting this argument can accept.

Fourthly, the premise that states "since rational investigation is a source other than the Qur'an and the Sunnah, it would therefore be illegitimate to refer to it", is extremely misleading. Rational investigation is not a source of knowledge. Rather, it is a methodology to be used to extract knowledge from its sources. Even if someone claimed that the Qur'an and the Sunnah presented their own methodology for the extraction of knowledge, we would still need a separate methodology - or at least certain definite principles - to extract its proposed methodology.

Fifthly, it must be asked what the "comprehensiveness" of the Qur'an and the Sunnah implies. Does it imply that these two sources of knowledge have mentioned everything that man needs in any manner whatsoever? This is definitely wrong. This is because the Quran is a book of guidance. It is not a book of science, philosophy or any other science for that matter. So, it only contains matters that are pertinent to man's otherworldly felicity. However, does it contain everything related to man's felicity in an explicit manner or does it simply mention general rules regarding this subject? It is also obvious that the first option is incorrect. Indeed, Imam Sadiq said: "It is up to 
us to give you general principles and for you to draw the necessary conclusions from these" (Ibn Idris Hilli 2011: III/575). Thus, for those philosophical problems which are not related to man's otherworldly felicity or which are specific problems that religion has not addressed it is permissible to refer to the science of philosophy. So, the conclusion of this argument is not as general as the claim it is attempting to prove.

Finally, it is interesting to note that a similar objection has been leveled against prophethood and revelation. Some atheists say that the knowledge that revelation provides is either in accordance with reason or it is not. If it is in accordance with reason, then there is no use for it. In this case, God should not send it since He does not do anything without a purpose. If it is not in accordance with reason it undermines the foundations upon which it rests. In this case, God should not send it since it would misguide man and lead him away from the truth. Thus, in either case God should not send revelation. The answer to this objection, as well as to the objection we are talking about, is the same. Just because something performs something that is also performed by another thing does not mean that either of the two is useless. Rather, each of them reinforces the other - which is something that they could not do if they were alone (Hilli 1993: 470).

$2^{\text {nd }}$ Objection: Useful Knowledge Belongs Solely to the Pious

\section{Objection:}

According to the Qur'an and the Sunnah, useful knowledge belongs solely to the pious. For example, in the $13^{\text {th }}$ verse of Surah "Ghafir", God says, "And no-one remembers except the one who repents". Also, in the $2^{\text {nd }}$ verse of Surah "Talaq", God says, "If someone is pious, then God will give him a way of escape". There are also traditions from the Infallibles that reinforce this matter, such as the following tradition from Imam al-Sadiq: "Knowledge is paired with action. So, the one who knows, acts and the one who acts, knows. Knowledge calls out to action. If it answers [its call, then it stays] otherwise it leaves" (Kulayni 1990: I/114). However, Logic belongs to both pious people and impious people. Therefore, rational investigation is not an instance of useful knowledge. Since it is useless, it is impermissible to delve into rational investigation (Jawadi Amuli 1985: 105-106).

\section{Critique:}

The first objection that can be leveled against this argument is that it has been presented in a rational format, using the second form of the cat- 
egorical syllogism, the middle term of which is "that which belongs to the pious". Thus, the conclusion of this argument contradicts the methodology employed in it.

Secondly, the first premise of this argument is contradicted by the rational arguments that the Qur'an presents to the disbelievers and hypocrites. If the aforementioned premise were indeed valid, then these arguments should be useless and impermissible - since they do not solely belong to the pious. Or, if it were useful knowledge, then the disbelievers should not enjoy it and understand it. It is obvious that both of these conclusions are unacceptable. This is because there is nothing in the Qur'an that is useless and impermissible. "Falsehood does not approach it from before it or from behind it". Also, if the disbelievers do not understand the arguments of the Qur'an, then how can they be guided by it? Unless someone says such arguments are meant for them after they have repented and become pious. In this case, once again, they would be useless.

Thirdly, we do not accept the evidence for the first premise of this argument. In other words, at most, these verses state that all pious individuals have useful knowledge. However, logically speaking, the converse of a universal positive proposition is particular. Thus, if all pious people have useful knowledge, this implies that some of the people who have useful knowledge are pious. However, we cannot conclude from this that everyone with useful knowledge is pious; rather, some of the people with useful knowledge are pious.

Fourthly, if this argument were indeed valid, then it would not be limited to the rational sciences; rather, it would also include the transmitted sciences such as grammar, the principles of jurisprudence, the sciences of Hadith, etc. This is because these sciences are also not limited to pious people; rather impious people also enjoy them. However, this is not something that the proponents of this argument can agree with.

What is more, it is possible to say that the aforementioned verses have nothing to do with the first premise; rather, they want to state something else. What these verses want to state is the knowledge that is useful in the Hereafter and in the spiritual progression of man to the ultimate goal for which he has been created solely belongs to the pious. The impious also possess useful knowledge; however, it is useful for them in this world. For example, a person may learn logic and philosophy and use these to make a living. He may not have any religious intentions in the acquisitions of these sciences. It is clear that these sciences only help him in this world. This depends upon the intention of the person acquiring the knowledge. Thus, this argument should be worded in the following manner: Only the pious possess knowledge that is useful in the Hereafter. The rational sciences that are 
used for worldly purposes are also possessed by the impious. Thus, the rational sciences that are used for worldly purposes are not instances of knowledge that is useful in the Hereafter. However, this does not mean the rational sciences are absolutely impermissible. If the rational sciences are used for otherworldly ends, they would fall outside of this argument. This is why the person making this argument wants to draw this very conclusion.

Finally, even though the rational sciences that are used for worldly purposes fall within the jurisdiction of this argument, we cannot say that they are impermissible. Just because something is not useful in the Hereafter it does not mean that it is impermissible. Otherwise, countless actions would be sins. When they say that actions that have no purpose are impermissible, they refer to actions that have no purpose at all, not to actions that have no other-worldly purpose.

\section{$3^{\text {rd }}$ Objection: Rational Investigation Leads to the Rejection of the Apparent Meanings of Sacred texts}

\section{Objection:}

If rational investigation were legitimate, then it would be permissible for one to reject the apparent meanings of the sacred texts - such as the Quran and the Sunnah. This is because very often, rational investigation leads to conclusions that contradict the apparent meanings of these texts. For example, the philosophers say that their rational demonstrations lead to the conclusion that it is necessary for God's knowledge to be one with His essence and for it to be presential in nature. However, this is a meaning of knowledge that ordinary people are unaware of and cannot comprehend. Thus, the conclusions of rational investigation lead to the rejection of the apparent meaning of religious texts that mention God's knowledge. Also, some people like Avicenna say that God's will is the same as His knowledge. However, this is not what people normally understand when they hear the word "knowledge". Thus, if we adhered to the conclusions of philosophy, then it would be necessary for us to interpret those statements of religious scripture that refer to God's knowledge in a way that ordinary people are unaware of and cannot understand. However, this is invalid; rather, it is necessary to interpret sacred texts in a manner that is not contrary to what ordinary human beings can understand. This is because - as the science of the Principles of Jurisprudence tells us - religion uses words to refer to those meanings that the people it is addressing usually understand from them. Otherwise, it would inform them that it had something else in mind. Since, if it did not do so, it would lead to treachery and misguidance, which is impossible (Jawadi Am- 
uli 1985: 86). However, it has not mentioned anything to the contrary. Thus, it is necessary to interpret these scriptures as ordinary people understand them and to reject rational investigation.

\section{Critique:}

First of all, this objection has been presented in the form of an exceptive syllogism, the first premise of which is a conjunctive conditional proposition and the second being a rejection of the antecedent of the first premise. Thus, if the conclusion of this argument were true, then it would nullify the argument itself.

Secondly, this argument is more specific than the claim it is attempting to prove. This is because it has been claimed that rational investigation into religion is absolutely impermissible. However, this argument cannot prove the absolute impermissibility of rational investigation; rather, it only proves the impermissibility of a specific type of rational investigation, i.e. the one whose premises are theoretical in nature. The reason for it is that this is the type of rational investigation that often leads to a rejection of the apparent meaning of religious texts. If the material of rational investigation is primary self-evident propositions, then this rejection does not occur.

Thirdly, upon careful consideration, this argument has nothing to do with the claim at all. This is because the person making this argument seeks to undermine rational investigation as a method of inquiry into religious verities - regardless of the material used in it. However, as the previous objection clarified, a rejection of the apparent meanings of religious texts does not stem from the method per se, but rather from the material utilized in it.

Fourthly, if this argument were valid, it would mean that all forms of investigation would be invalid - not just rational investigation. This is because when such forms of investigation use theoretical premises they also sometimes come into conflict with the apparent meanings of religious texts. For example, sometimes, some of the rules of grammar lead to interpretations of religious texts that contradict the apparent meanings of the text in question. If the aforementioned argument were correct, then it would lead to the impermissibility of the science of grammar. The same can also be said of the experimental sciences. However, this is something that the person making this argument cannot accept.

Fifthly, it seems that the person making this argument has not properly understood what the term 'apparent meaning' refers to. The reason for this is that it is necessary to examine all of the clues that surround the statement when deriving the apparent meaning of a statement. These clues can be connected to the statement, but they can also be distant from it in time and 
place. What is more, these clues can be verbal and they can also be rational. This is why experts in the science of the principles of jurisprudence make a distinction between the 'initial apparent meaning' and that which is derived after consideration. In fact, it is the second type of "apparent meaning" that must be accepted, not the first. Thus, while it is true that some of the conclusions of rational investigation contradict the first type, they do not contradict the second; rather, they play a role in its formation.

What is more, the examples that have been mentioned in this argument have nothing to do with the principle mentioned in it. The principle mentioned in this argument is that it is necessary to interpret the words used in religious texts as referring to meanings that are understood by ordinary people from those words. However, in the examples mentioned in this argument, this has indeed taken place. The only thing is that instances of those meanings have been discovered that ordinary people are unaware of. For example, in the case of God's knowledge, philosophy does not say that in religious texts the word "knowledge" refers to a meaning that is different from what ordinary people refer to (Tabatabai 2011: 119). When ordinary people hear this word, they take it to refer to a phenomenon that is self-evidently clear and that makes something else, i.e. the thing known, clear. In the case of God's knowledge, this is what this term refers to. However, the instances of this phenomenon are different. Some of them are united with the knower, while others are not. Ordinary people are accustomed to the second instance of this concept, and not to the first. However, this has nothing to do with the meaning of this term, but rather with an instance of this meaning. The aforementioned principle stating that it is necessary to interpret words used in religious texts as referring to meanings that ordinary people understand, and not to instances of those meanings that ordinary people are used to.

Finally, if this argument were indeed valid, then it would contradict itself. This is because there is no religious text that states it is necessary to interpret words used in religious texts as referring to the meanings that people ordinarily understand. The legitimacy of the apparent meanings of words is a concept that has been proven in the science of jurisprudence using a rational argument. This argument states that if God intended a meaning of a word to be different from that which the listener understands from it, then it would be necessary for Him to state this matter. This is because if He did not do so, it would lead to Him misguiding the people, which is impossible. However, under the assumption, He has not stated something that would lead us to reject the apparent meaning of these words. Thus, we have to conclude that these apparent meanings are indeed what $\mathrm{He}$ intends from them. As is only too apparent, this argument uses the rational method to arrive at the truth 
of this principle. What is more, the material utilized in it is also exclusively rational in nature.

\section{$4^{\text {th }}$ Objection: Rational Investigation was First Introduced in the Islamic World with Evil Intentions}

\section{Objection:}

History tells us that the rational sciences were first introduced in the Islamic world by the Abbasids, who sought to consolidate their power in this way. They spent lavish amounts of money on the translation of the works of the Greeks, Indians and Persians in order to draw the intellectuals away from the Infallible Imams and towards themselves. Since it was founded with illegitimate intentions, rational investigation must be rejected (Jawadi Amuli 1985: 86).

\section{Critique:}

First of all, this objection has been presented in the form of an exceptive syllogism, the second premise of which is the affirmation of the precedent of the first. Thus, its conclusion contradicts the methodology utilized in it. So, it must be rejected.

Secondly, if this argument were true, then it would lead to a rejection of many other sciences, such as Arabic grammar, the principles of jurisprudence, etc. This is because if the rational sciences were founded with such intentions, then there would be no reason to say that these sciences were not founded for the same, if not worse, reasons.

Thirdly, we cannot accept the first premise of this argument. There is no necessary connection between the ill intentions of the foundation of a science and its use being impermissible. If someone made a sword to kill someone, does this imply that it is impermissible to use that sword to cut a watermelon? Rather, it is impermissible to use a science for illegitimate reasons, not to use a science that was formed for illegitimate reasons.

Fourthly, the idea that these sciences were founded for these reasons is something that is not provable; rather, history tells us that it was the Infallible Imams - especially Imam Ali - who were the founders of these sciences in the Islamic world. A casual look at the sermons of the Nahj al-Balagah is a testament to this fact.

Finally, there is something implied in this argument, i.e. the idea that since these sciences were founded for this reason, they lead to it. In other words, since these sciences were founded with the intent of drawing people 
away from the Infallible Imams, they naturally lead to such a result. However, this is something that can be debated. Aside from the fact that there is no necessary connection between the precedent and the antecedent of this proposition, history tells us that in many instances the converse has occurred. So, we see many sages and philosophers accepting the sovereignty of the Imams because they were well-grounded in the rational sciences. One instance of this is the late Muhaqqiq Dawani. In his autobiography, he narrates why he accepted the Shi' ite faith. It is ironic to note that this sage was a descendent of the first caliph. He says that, having studied philosophy for many years, he realized that his own forefather did not understand the lofty conclusions that he himself made. Thus, he concluded that there was no way that he deserved to be the successor to the Prophet.

\section{$5^{\text {th }}$ Objection: Rational Investigation \\ Sometimes Leads to Incorrect Results}

\section{Objection:}

If rational investigation were a path that led the one who traversed it to the truth, then those who traversed this path would always attain the truth. However, sometimes those who rationally investigate matters reach incorrect conclusions. The evidence for this is the claim that there are contradictions that exist between the results of the rational demonstrations of philosophers. Since they contradict one another, it is impossible for all of these conclusions to be correct. Thus, rational investigation is not a path that leads to the truth (Jawadi Amuli 1985: 84).

\section{Critique:}

First of all, this objection has been presented in the form of a conjunctive exceptive syllogism, the second premise of which is a negation of the antecedent of the first. Thus, its conclusion contradicts the methodology used in it.

Secondly, this objection can be equally leveled against other sciences, such as grammar. This is because grammarians, for example, often contradict one another. Thus, the beliefs of some of them must be incorrect. Based upon the aforementioned argument, grammar should not be a path that leads to correct results.

Thirdly, it must be asked what the phrase "then those who traversed this path would always attain the truth", means. Does it mean "then those who traversed it properly would always attain the truth", or does it mean "then 
those who traversed it even in an improper manner would always attain the truth"? In the first case, we do not accept the second premise of this argument, i.e. the idea that some people who properly traverse this path do not attain correct conclusions. However, in the second case, we cannot accept the first premise, i.e. the idea that "if rational investigation was a path that led the one who traversed it to the truth, then those who traversed this path in any way whatsoever would always attain the truth". This would be like saying that "if such and such a highway lead to Vegas, then everyone who took it would get there". This is because not attaining the goal to which the road claims to lead can stem from one of two things. It can stem from the road not leading there and it can stem from the person not sticking to it. In order to prove that a path or a method is flawed, one has to show that no-one has attained, nor will ever attain, the goal even though they use it properly. This is not something that this argument has shown.

Finally, this proof contradicts the claim it is attempting to prove, i.e. the idea that rational investigation is absolutely impermissible. This is because if those who use rational investigation contradict one another, then not only does this demonstrate that some of them are wrong, but it also demonstrates that some of them are correct. This is because just as it is impossible for two contradictory statements to be true, it is also impossible for both of them to be wrong. Therefore, some of the conclusions of rational investigation are correct. Thus, it must be a path that leads to the truth, at least some of the time. This is enough to contradict the claims of our opponent in this debate.

\section{$6^{\text {th }}$ Objection: Rational Investigation \\ Leads to a Vicious Circle of Argumentation}

\section{Objection:}

If rational investigation were a legitimate source of knowledge of religious verities, then its legitimacy would stem either from rational investigation or some other source. In the first case, it would lead to a vicious circle of argumentation, which is invalid. In the second case, it would have to stem from religion. If it stemmed from religion, then the legitimacy of the religious text from which one derived the legitimacy of rational investigation would stem either from itself or from rational investigation. In the second case, a vicious circle of argumentation would once again arise. In the first case, religion would not need rational investigation for its legitimacy. Thus, rational investigation is illegitimate and one can take recourse to religion without the need of rational investigation (Ibid.: 107). 


\section{Critique:}

First of all, this argument comes in the form of an exceptive syllogism, the antecedent of the first premise of which is a disjunctive proposition and the second premise of which is a rejection of both sides of this antecedent, which is accomplished by means of two exceptive syllogisms. Thus, the conclusion of this argument contradicts the methodology used in it and therefore it must be rejected.

Secondly, it is possible to present a similar argument for the illegitimacy of referring to religion. This is because the legitimacy of referring to religion would stem either from reason or from religion itself. In the first case it would lead to a vicious circle of argumentation - based upon the aforementioned argument. The same would be true if we attempted to prove the legitimacy of religion using religion itself. So, if this argument were sound, it would prove the illegitimacy of religion.

Thirdly, there is something implied in this argument, i.e. the idea that the legitimacy of referring to reason is theoretical. Based upon this premise, the person making the argument asks what the evidence for this legitimacy is. However, the truth of the matter is that rational premises are not all theoretical in nature. Some of them are self-evident. Such premises do not need any evidence for their legitimacy (Muzaffar 2008: 28). If it is sometimes stated that these premises are "the evidence for themselves", then what this really implies is that they do not need any evidence. This resembles the time when they say: "God is His own cause". What this implies is that God does not need a cause, not that He needs a cause, but His cause is Himself (Misbah 1991: 33). So, no vicious circle of argumentation ensues.

\section{$7^{\text {th }}$ Objection: People Often Attain the Truth without Rational Investigation}

\section{Objection:}

If rational investigation - that comes in the form of logic - were necessary in order to attain the truth, then those individuals who did not use logic in their pursuit of the truth would not attain it. However, many people who seek out the truth do attain it even though they do not use reason or logic in their inquiries. Actually, some of these people have not ever studied logic and are unaware of its principles. So, reason and logic are unnecessary for the attainment of the truth. Since they are unnecessary endeavors, they are impermissible (Jawadi Amuli 1985: 85). 


\section{Critique:}

First of all, this argument has been presented in the form of a composite syllogism, the first syllogism of which is an exceptive syllogism, whose second premise, in turn, is a denial of the antecedent of the conditional premise, which is its first premise. The second syllogism is also an exceptive syllogism and its second premise is an affirmation of the precedent of the first premise. Thus, the conclusion of this argument contradicts the methodology used in it. So, it cannot be accepted.

Secondly, it seems that the person making this objection is of the opinion that the rules of rational investigation that are manifested in the rules of logic are conventional laws that were formed by Aristotle. This is not the case. As Aristotle himself admitted, the rules of logic are embedded within human nature. All that the Stagirite did was to organize them and clarify those that were ambiguous (Muzaffar 2008: 203). Thus, the abovementioned argument - if valid - only leads to the conclusion that the study of logic is unnecessary and therefore impermissible. However, it cannot lead to the conclusion that natural logic is unnecessary and impermissible which is what the person making the argument wants to prove. Thus, this argument leads to a conclusion that is more specific than the claim it is attempting to prove.

Thirdly, we cannot even accept that this argument leads to the absolute uselessness of the discipline of logic. This is because while it is true that many people can use the basic laws of logic to arrive at simple truths, experience has shown that they cannot do so in complex problems. Thus, we once again see that this argument leads to a conclusion that is more specific than the claim it is attempting to prove.

Finally, if this argument were valid, then it would lead to the uselessness and impermissibility of many other sciences, such as grammar, the principles of jurisprudence, etc. This is because many people arrive at correct conclusions without them. For example, an Arab may read a tradition or a verse of the Qur'an and understand its meaning even though he may have never read a single book of Arabic grammar. Can we conclude from this that Arabic grammar is absolutely useless and its study impermissible?

Finally, if this argument were valid, it would also lead to the uselessness of religion. This is because, according to the Quran, religion is something natural to man. Man is born a monotheist. Religion simply comes to emphasize what is embedded within man's very nature. The Prophet said that every newborn was born upon the [divine] nature. It is its parents that make it Jewish or Christian. 
$8^{\text {th }}$ Objection: Reality does not Observe Formulated Laws

Objection:

If rational investigation were necessary for the attainment of the truth, then it would mean that the truth would depend on the laws of logic and reason. If this were true, then it would mean that in order for something to be true and real it would have to depend on the rules of reason and logic. However, this is impossible as the laws of reason and logic are laws that were gradually formulated by man. However, the truth existed long before the laws of logic were formulated. It is impossible for reality to observe laws that are formulated by human beings. For example, traffic laws tell us that when you see a red light it is necessary for your car to stop. However, reality does not follow this law in the sense that if you lose control of your car you might pass the intersection even though the light is red. The same is the case with logical rules. Logic tells us that if you formulate an argument using the first form of the syllogism, the conclusion will be true, provided that the conditions for this form are met. However, just because logic tells us that the conclusion is necessary under these conditions does not imply that it must necessarily be so in the external world (Jawadi Amuli 1985: 85).

\section{Critique:}

First of all, this argument has been formulated as an exceptive syllogism, the second premise of which is the negation of the antecedent of the conditional proposition, which is the first one. Thus, the conclusion of this argument contradicts the methodology used in it. So, it must be rejected.

Secondly, we never claimed that rational investigation is necessary for the attainment of the truth. Our claim is that rational investigation is a sufficient way to attain the truth. It is obvious that there is a difference between the two.

Thirdly, there is no necessary connection between the precedent and the antecedent of the first premise of this argument. The person making it has confused the truth as an epistemological reality with the truth as an ontological one. Rational investigation is a sufficient means to understand the truth in the mind. However, it is not necessary for the occurrence of the truth in the external world. The antecedent of this premise should mirror its precedent. Thus, the first premise of this argument should be stated in this way: "If rational investigation were necessary for the attainment of the truth by the mind, then it would mean that the attainment of the truth by the mind would depend on the laws of logic and reason". However, in this case the second premise of this argument has nothing to do with the first. This 
is because it is the occurrence of the truth in reality that has nothing to do with rational investigation, not its occurrence in the mind. So, depending on the meaning of the antecedent of the first premise, either the first premise is wrong or the second premise has nothing to do with the first. As a result, this argument is incorrect.

What is more, the proof that has been mentioned for the incorrectness of the antecedent of the first premise is incorrect. This is because it rests upon the assumption that the laws of logic which are the subject of debate are those that were penned by Aristotle. This is why we are currently debating the laws of logic that are natural to man and that Aristotle only discovered, not formulated.

Finally, the statement, "It is impossible for reality to observe laws that are formulated by human beings", has nothing to do with the topic at hand. This is because the laws that it refers to are conventional laws that are not derived from reality. This is indeed true of the example mentioned, i.e. traffic laws. However, not all laws are conventional in nature. For example, the laws of physics are not like this. Physical reality never contradicts these laws since they have been discovered from this very reality. The laws of logic are of the same nature.

\section{$9^{\text {th }}$ Objection: Logic Provides no General Law for the Delineation of the Truth of the Material used in Rational Investigation}

\section{Objection:}

Even though Logic provides rules for the form of rational investigation by means of which one can distinguish conclusive arguments from barren ones, there are no rules in Logic for the evaluation of the material of those arguments. Logic simply tells us that the material used in argumentation should either be self-evident premises or terminate at self-evident premises. It also tells us that there are six categories of self-evident premises. However, it does not tell us how to assess whether a given premise is self-evident or not, and if it is, what category of self-evident premises it falls under. Thus, there is no choice but to refer to religious texts in this dimension of argumentation, i.e. the material of argumentation. This is because these texts are immaculate and necessarily true (Ibid.: 87).

\section{Critique:}

First of all, the conclusion of this argument is more specific than the claim it is attempting to prove. This is because the person presenting it seeks 
to reject the rational sciences completely. However, if this argument were valid, then all it could prove was the impermissibility of the section on material in logic. It cannot prove the impermissibility of the section on the form of argumentation in logic.

Secondly, we cannot accept the idea that the science of logic presents no general rule to delineate which premises are certain and which are not; rather, the definitions of the self-evident positions that it presents would be the general rules for such a delineation.

It is possible that what the person making this objection has in mind is that the science of logic does not prove why such self-evident premises are correct; rather, this is something that is the responsibility of the science of epistemology (Fayyazi, Sharifi \& Rezayi 2008: 112). While this is true, this objection does not prove the uselessness of all of the rational sciences; rather, it simply proves that in and of itself, logic is not sufficient. However, this is not something that we deny.

Thirdly, the conclusion that the person making this argument derives is that with respect to the content of argumentation it is necessary to refer to the teachings of the Infallible Imams, not reason. However, this conclusion is misleading and invalid. The reason for this is that with regards to matters of faith - where nothing short of certainty is sufficient - it is only possible to refer to the teachings of the Imams when three premises have been proven. The first one is that the saying was actually said by the Imams. This is usually done when it is demonstrated that the saying has been consecutively transmitted. Secondly, it must be proven that the Imam did not make the statement under duress or in a state of dissimulation. Finally, if the saying is not explicit, then it must be proven that the apparent meaning of the words used are what the Imam actually intend. However, all three of these premises are only proven using reason. For example, the validity of the consecutively transmitted tradition is proven by stating that it is rationally improbable that such a vast number of individuals fabricate such a lie. Also, the second and the third premises are only proven using linguistic principles such as the principle of generality, etc. However, the validity of such verbal principles is only proven using reason. Thus, if the conclusion of this argument were valid, it would contradict itself. So, it is necessary to reject it.

Finally, the immaculateness of the Imams is something that cannot be proven by anything other than reason. This is because it is something that rests on the truth of the Qur'an and the sayings of the Prophet. However, the truth of their words rests upon a rational demonstration. Thus, the conclusion that this argument is attempting to derive contradicts itself. 


\section{0 $0^{\text {th }}$ Objection: Rational Demonstration Rests \\ Upon the Validity of Causation}

\section{Objection:}

In Logic, argumentation is divided into induction, deduction, and comparison. Subsequently, deduction is divided into five categories based upon the nature of the premises utilized in it. Out of all of these forms of argumentation, only one type is said to grant certainty, i.e. demonstration. However, not all demonstration leads to definite and certain conclusions. It is only the "limmi" demonstration that does so. In this form of demonstration, the attribution of the minor term of the argument with the middle term is the cause of the attribution of the major term with the minor term. Thus, if causation were invalid, no form of rational argumentation would lead to definite and certain conclusions. However, causation is invalid. Thus, there is no form of rational argumentation that leads to certain conclusions. The reason why causation is invalid is that it leads to a semblance between God and His creatures or a limitation of God, both of which are invalid. This is because the effect has to resemble its cause. This is something that philosophy admits to. Thus, causation is an incorrect notion (Mozaffari 2006: 128).

\section{Critique:}

First of all, this argument has been presented in the form of an exceptive syllogism, the second premise of which is the affirmation of the precedent of the conditional proposition, which is the first one. Thus, the conclusion of this argument contradicts the methodology used in it. Hence, it must be rejected.

Secondly, this argument is more specific than the claim it is attempting to prove. This is because the only thing that this argument proves is that logical argumentation that comes in the forms of argumentation that have been mentioned in the aforementioned objection is invalid. However, it does not show the illegitimacy of other forms of argumentation such as conversion, contradiction, etc. So, if we have a premise that is self-evidently true, we can conclude that the converse is also true and that its contradiction is necessarily false. This is why the person making this argument completely rejects all forms of rational investigation. Thus, the claims of this person and his argument do not parallel one another.

Thirdly, we cannot admit the evidence for incorrectness of causation mentioned above. While it is true that there has to be a semblance between cause and effect (Tabatabai 2010: 22), this does not imply that the two are complete- 
ly the same. And, it is the latter that is impossible (Zanuzi 2015: 134). If the Qur'an states that "there is nothing like (mithlihi) Him", it also states: "and for God there is the greatest of parables (al-mathal al-ala)". So, a distinction must be made between the two and therefore this argument is incorrect.

What is more, if causation were incorrect, then there would be no neces= sary connection between the premises of this or any argument for that matter with its conclusion. This is because this necessity stems from the fact that the premises of the argument are the cause for its conclusion. Thus, the conclusion of this argument - if definite - contradicts its argument. So, it must be rejected.

\section{$11^{\text {th }}$ Objection: There are no Universal Truths}

\section{Objection:}

If rational investigation wants to arrive at stable and universal conclusions, then it is necessary for at least one of its premises to be stable and universal. This is why such investigation is impossible, since there is nothing stable or universal in the universe. Everything is in a state of movement and there is no similarity between things. Thus, rational investigation cannot arrive at stable and universal conclusions. Since it cannot arrive at any stable and universal conclusions, it is useless and impermissible (Jawadi Amuli 1985: 108).

\section{Critique:}

First of all, this argument has been presented in the form of a compound syllogism, both components of which are exceptive syllogisms. Thus, the conclusion of this argument contradicts the methodology utilized in it and must therefore be rejected.

Secondly, if there are no stable and universal truths, then the premises and conclusion of this argument cannot be universal and stable. Therefore, they have no value.

Thirdly, we cannot accept the idea that everything is in a state of instability or that there is nothing common to more than one being. This is something that both reason and religion rejects. At least it is possible to say that there is one being that is stable, i.e. God.

Fourthly, even if we assumed that everything was in a state of change or that there was nothing common between more than one being, this would not negate the possibility of arriving at stable and universal conclusions. Take an apple seed into consideration. It gradually changes and transforms 
into an apple tree. So, it is in a state of change and is unstable. No two moments of it are the same. Nevertheless, we can point to one moment and make some necessary, universal and stable conclusions regarding it. For example, we may say that at a particular moment in time the shape of the seed was necessarily "round". At that moment, the shape of the seed was always round and this shape was stable for it (Fayyazi 2014: I/143). We could also say something similar for universality. Even if there was nothing in common to more than one thing, we could still make universal statements. For example, we could say that "no two things are the same". Thus, the instability and divergence of beings do not negate universality, necessity and stability in an absolute manner.

\section{$12^{\text {th }}$ Objection: The Usage of Rational Investigation Implies that the Qur'an and the Sunnah Need Something Other than Themselves}

\section{Objection:}

If reason was a method used to understand the Quran and the Sunnah, then these two sources of wisdom would need something other than themselves. However, the Qur'an and the Sunnah do not need anything other than themselves. Thus, reason is not a method to be used to understand the Qur'an and the Sunnah (Jawadi Amuli 1985: 88).

\section{Critique:}

First of all, this argument has been presented in the form of an exceptive syllogism, the second premise of which is a rejection of the antecedent of the conditional proposition, which is the first one.

Secondly, if this argument were correct, it would lead to the conclusion that other sciences - such as grammar - cannot be used to understand the Quran and the Sunnah. However, this is something that the person making this argument cannot admit to.

Thirdly, we cannot accept the necessary connection between the precedent and the antecedent of the first premise here. This is because reason, as a method that is used to understand the Qur'an and the Sunnah, does not lead to these sources of wisdom being in need of something other than themselves; rather, it implies that the person who seeks to derive knowledge from them is deficient and needs something. For example, the human body tells us everything that we need in order to combat diseases and remain healthy. However, this does not mean that we do not need medicine or experimentation or that these things are useless. Similarly, the Qur'an and the Sunnah contain all the 
rules that we need to secure our otherworldly felicity. However, this does not mean that we do not need a method to derive these rules.

What is more, rational investigation is not something parallel to the Quran and the Sunnah, such that their usage would imply that these two entities needed something other than themselves. Rather, rational investigation is something that the Qur'an and the Sunnah also contain. Thus, the first premise of this argument is not certain.

Finally, we cannot accept the second premise of this argument, i.e. the idea that the Qur'an and the Sunnah do not need anything other than themselves; rather, there are numerous instances where the Qur'an and the Sunnah have needed things other than themselves to impart the guidance that they present. The only being that is absolutely self-sufficient is God.

\section{The $13^{\text {th }}$ Objection: The Qur'an Prohibits us from Following the Disbelievers}

\section{Objection:}

If we use logic in our religious investigations, then we are following disbelievers. This is because the rules of logic were formulated by Aristotle, who was a disbeliever. However, the Qur'an prohibits us from following the disbelievers. Thus, we should not use logic in our religious investigations (Ibid.: 106).

\section{Critique:}

First of all, this argument has been presented in the form of an exceptive syllogism, the second premise of which is a rejection of the antecedent of the first. Thus, if the conclusion of this argument is true, then it would contradict the methodology it uses. So, it must be rejected.

Secondly, if this argument were valid, then it would lead to the rejection of many other sciences. This is because logic is not the only science that was founded by disbelievers. However, this is not something acceptable.

Thirdly, the rules of logic were not formulated by Aristotle. They exist in human nature. All Aristotle did was discover and organize them. If anyone formulated the laws of logic, it was God Himself. Thus, the first premise of this argument is not definite.

Fourthly, the faith of Aristotle is open to debate. He was a theist. However, his monotheism is a subject of discussion among historians. In any case, since this premise is not definite, the conclusion of the aforementioned argument is also such. 
The $14^{\text {th }}$ Objection: It is Impossible to

Gain Rational Understanding of God

\section{Objection:}

If rational understanding of God is impossible, then it is useless and impermissible to rationally investigate into matters of religion. However, it is impossible to gain rational understanding of God. Thus, it is useless and impermissible to rationally investigate into matters of religion. Reason tells us that God is infinite, while the mind is finite. Something finite cannot comprehend something infinite. What is more, religion has told us that the knowledge of God cannot be acquired by the mind. If the mind cannot comprehend God, how could it comprehend the other matters of religion? After all, these other religious matters depend upon the knowledge of God (Mozaffari 2006: 152).

\section{Critique:}

First of all, this argument has been presented in the form of an exceptive syllogism, the second premise of which is a rejection of the antecedent of the first. Thus, the conclusion of this argument contradicts the methodology used in it. So, it must be rejected.

Secondly, the conclusion of this argument is more specific than the claim it is attempting to prove. This is because this argument seeks to demonstrate that the mind cannot understand what God or other religious verities are. However, it does admit that this incomprehension is something that the mind comprehends and admits to. Thus, there is something about God and religion that the mind understands, i.e. that these truths cannot be comprehended by it. This is why the person making this argument is attempting to prove a very universal claim, i.e. the reason does not understand anything about religion whatsoever.

Thirdly, we cannot accept the idea that it is impossible for the mind to comprehend God. Of course, this is a subject that must be taken up independently. It is not the primary purpose of this paper. Nevertheless, it should not be left unsaid that the argument presented above is erroneous. This is because the reality of God is something infinite, with a common technical predication, not the concept of God. The concept of God is finite, with a common technical predication, even though it is infinite with a primary essential predication. The mind is finite with a common technical predication. For a problem to arise, the concept of God would have to be infinite with a common technical predication. It is only then that the container, i.e. 
the mind, would not have the capacity for that which it contained, i.e. the concept of God. However, this is not the case. Yes, since the reality of God is infinite with a common technical predication, it cannot be grasped by the mind. In fact, if religion tells us that it is impossible for the mind to understand God, then it refers to the reality of God, not the concept of God.

\section{Conclusion}

These were some of the arguments for the illegitimacy of the use of reason in the investigation of religious truths. As we have seen, all of them are more or less problematic. Aside from the objections that we have leveled against these pieces of evidence, there is also another problem that plagues them all. The Qur'an and the traditions of the Infallibles praise reason (al$-a q l$ ) and encourage contemplation of religious truths. If rational investigation is illegitimate, then why would religion encourage it? Of course, the proponents of the illegitimacy of rational investigation interpret these verses and traditions in another manner. The correctness or incorrectness of this interpretation is something that must be taken up in another place. Also, the same proponents also have religious proofs that indicate the illegitimacy of rational investigation. Many of these are traditions narrated from the Infallible Imams in which the later scorn philosophy and philosophers. The soundness of these traditions, as well as their purpose, is a topic that requires an independent investigation. For now, we think that what we have presented so far will suffice. Perhaps in the future a more thorough study will be possible.

Received: November $8^{\text {th }}, 2018$.

Accepted: December $20^{\text {th }}, 2018$.

\section{References}

The Holy Quran.

Fayyazi, Gholam Reza (2014), Ta’liqah ala Nihayah al-Hikmah, Qom, Muassisah Imam Khomeini, $2^{\text {nd }}$ edition.

Fayyazi, Gholah Reza; Sharifi, Ahmad Hosein \& Rezayi, Morteza (2008), Daramadi bar Marefat-shenasi, Qom, Mu'assasa Imam Khomeyni, $4^{\text {th }}$ edition.

Hilli, Hasan ibn Yusuf (1993), Kashf al-Murad fi Sharhi Tajrid al-I'tiqad, Tehran, Islamiyyah, $7^{\text {th }}$ edition.

Ibn Idris Hilli (2011), As-Sarair al-Hawi li Tahrir al-Fatava, Qom, Jami'ah al-Mudarrisin, $6^{\text {th }}$ edition.

Jawadi Amuli, Abdullah (1985), Hedayat dar Qor'an, Qom, Markaz Farhanghi Nashr Raja, $2^{\text {nd }}$ edition. 
Jawadi Amuli, Abdullah (2001), Ali ibn Musa ar-Rida wa al-Falsafa al-Ilahiyyah, Qom, Dar al-Isra, $2^{\text {nd }}$ edition.

Kulayni, Muhammad ibn Ya’qub (1990), Usul al-Kafi, translated by Jawad Mostafawi and Hashem Rasuli, Tehran, Islamiyyah.

Misbah, Muhammad Taqi (1991), Amuzeshe aqaed, Tehran, Sazman Tablighat Islami, $4^{\text {th }}$ edition.

Mozaffari, Hosein (2006), Bonyane Marsus: Falsafeye Eslami az Negahe Maktabe Tafkik, Qom, Muassisah Imam Khomeini.

Muzaffar, Muhammad Ridha (2008), al-Mantiq, Qom, Jami'ah al-Mudarrisin.

Tabatabai, Muhammad Husain (1991), al-Mizan fi Tafsir al-Quran, Beirut, Muassisah al-Alami li al-Matbu'at.

Tabatabai, Muhammad Husain (2010), Bidayah al-Hikmah, Qom, Jami'ah al-Mudarrisin, $27^{\text {th }}$ edition.

Tabatabai, Muhammad Husain (2011), Nihayah al-Hikmah, Qom, Muassisah Imam Khomeini.

Zanuzi, Mulla Abdullah (2015), Muntakhab al-Khaqani fi Kasf al-Haqaiq al-Irfani, Tehran, Mowla. 